\title{
The effect of the TiC particle size on the preferred oxidation temperature for self-healing of oxide ceramic matrix materials
}

\author{
L. Boatemaa ${ }^{1, \star}$ (1), J. C. Brouwer ${ }^{1}$, S. van der Zwaag $^{2}$, and W. G. Sloof ${ }^{1}$ \\ ${ }^{1}$ Department of Materials Science and Engineering, Delft University of Technology, Mekelweg 2, 2628 CD Delft, The Netherlands \\ ${ }^{2}$ Faculty of Aerospace Engineering, Delft University of Technology, Kluyverweg 1, 2629 HS Delft, The Netherlands
}

Received: 29 September 2017

Accepted: 27 December 2017

Published online:

4 January 2018

(C) The Author(s) 2018. This article is an open access publication

\begin{abstract}
The effect of particle size on the oxidation kinetics of TiC powders is studied. Different sizes of $\mathrm{TiC}$ powder ranging from nanometre to submillimetre sizes are investigated. The samples are heated at different heating rates from room temperature up to $1200{ }^{\circ} \mathrm{C}$ in dry synthetic air. The Kissinger method for analysis of non-isothermal oxidation is used to estimate the activation energy for oxidation of the powders and to identify the active temperature window for efficient self-healing. The master curve plotting method is used to identify the model which best describes the oxidation of TiC powders, and the Senum and Yang method is used to approximate the value for the Arrhenius constant. The oxidation of $\mathrm{TiC}$ proceeds via the formation of oxycarbides, anatase and then finally the most stable form: rutile. The activation energy is found to be a strong function of the particle size for particle sizes between $50 \mathrm{~nm}$ and $11 \mu \mathrm{m}$ and becomes constant at larger particle sizes. The data demonstrate how the minimal healing temperature for oxide ceramics containing $\mathrm{TiC}$ as healing particles can be tailored between 400 and $1000{ }^{\circ} \mathrm{C}$ by selecting the right average $\mathrm{TiC}$ particle size.
\end{abstract}

\section{Introduction}

Embedded titanium carbide (TiC) particles are being considered as a potential healing agent to autonomously repair crack damage in oxide ceramics used in high-temperature applications [1]. For such (extrinsic) self-healing ceramics, microscopic cracks in the material will also intersect the sacrificial healing particle and allow atmospheric oxygen to reach it.
The local supply of oxygen via the open cracks to the intersected $\mathrm{TiC}$ particles will cause them to oxidize, leading to the formation of $\mathrm{TiO}_{2}$ which both fills the crack and adheres strongly to the faces of the crack [2]. Hence, the so-called healing reaction leads to a partial or complete recovery of the mechanical properties of the material and an extension of the lifetime of the component. To be a successful strategy, it is important that the oxidation reaction takes

Address correspondence to E-mail: 1.boatemaa@tudelft.nl 
place at the prevailing conditions (in particular the right temperature) and with the right kinetics. A general analysis of the required properties of the healing particles leading to autonomous self-healing at high temperature can be found in [2].

However, the cited analysis did not specify the minimal temperature window required to trigger the healing reaction. Of course, the required minimal temperature to trigger the healing reaction depends primarily on the chemical stability of the healing material in an oxygen-containing environment. This dependence has already been demonstrated (but apparently not been appreciated) in the combined first-generation studies on self-healing of $\mathrm{Al}_{2} \mathrm{O}_{3}$ or $\mathrm{Si}_{3} \mathrm{~N}_{4}$ filled with $\mathrm{SiC}$ or $\mathrm{Ni}$ particles [3-7]. In these studies, the crack healing ability was studied as a function of both temperature (from 900 to $1400{ }^{\circ} \mathrm{C}$ ) and time (between 1 and $300 \mathrm{~h}$ ) and widely different values were obtained for different particle sizes.

While the optimal healing temperature has been shown to vary significantly with the chemical composition of the healing particle and to a lesser degree of that of the matrix material, very few studies, with the exception of [8], performed a systematic study on the effect of particle size on the healing kinetics given a fixed composition for both the particle and the matrix. In their study, Nakao and Abe [8] measured the strength recovered by high-temperature oxidation of alumina containing $18 \mathrm{vol} \% \mathrm{SiC}$ particles of size 270, 30 and $10 \mathrm{~nm}$. They reported that reducing the size of $\mathrm{SiC}$ reduced the oxidation/healing temperature from 1200 to $950{ }^{\circ} \mathrm{C}$, due to the faster oxidation kinetics at lower particle sizes.

Recently, the ability of 2- $\mu$ m-sized TiC particles to heal surface cracks in alumina has been studied by Yoshioka et al. [1]. Healing of two different composites containing 15 and $30 \mathrm{vol} \%$ of $\mathrm{TiC}$ was studied as a function of temperature ranging from 400 to $800{ }^{\circ} \mathrm{C}$ in air and a fixed time of $1 \mathrm{~h}$. Full strength was obtained for a composite containing $30 \mathrm{vol} \%$ of $\mathrm{TiC}$ upon annealing in air at $800{ }^{\circ} \mathrm{C}$ for $1 \mathrm{~h}$. Also, in situ healing of these alumina composites was demonstrated [9]. Surface cracks were healed when the material was exposed in a combustion chamber with a high-velocity exhaust gas mixture at approx. $1000{ }^{\circ} \mathrm{C}$ and a low oxygen partial pressure.

The oxidation behaviour of bulk TiC has already been investigated as a function of temperature (from 600 to $1200{ }^{\circ} \mathrm{C}$ ) and oxygen partial pressure $(13-100 \mathrm{kPa})[10,11]$. The observable trend in these studies is that oxidation proceeds parabolically from 600 to $800{ }^{\circ} \mathrm{C}$ and switches to linear kinetics at higher temperatures and higher oxygen partial pressures. Four steps were identified during the transformation of $\mathrm{TiC}$ powders to $\mathrm{TiO}_{2}[12,13]$. The first step involves the substitution of atomic oxygen for the carbon present at the interstitial vacancies of the $\mathrm{TiC}$ lattice leading to the formation of the oxycarbides/ titanium suboxide layer. In the next step, the titanium suboxides oxidise into amorphous titanium dioxide and further crystallize to anatase. In third stage, the crystallization of anatase continues and the resulting volume expansion leads to the cracking of the oxide layers, and this provides fast short-circuit diffusion paths oxidation. In the fourth and final step, anatase is formed continuously and rather rapidly transformed into rutile. The rate-determining step is the diffusion of oxygen through the already formed oxide layers.

With TiC having been identified as a potential healing agent for alumina [2], the current work focusses on the determination of the effect of TiC particle size on its oxidation kinetics in order to explore the possibility to lower the minimal healing temperature of alumina containing $\mathrm{TiC}$ to temperatures below $1000{ }^{\circ} \mathrm{C}$. To this aim, differential thermal and thermogravimetric analyses are performed for TiC powders of different particle sizes over the temperature range from room temperature to $1200{ }^{\circ} \mathrm{C}$. The kinetic triplet, i.e. the activation energy, the reaction model and the Arrhenius constant, is determined for all powders and such information, in principle, allows the prediction of the optimal healing temperature for any inert ceramic containing $\mathrm{TiC}$ particles as the discrete, extrinsic healing agent.

\section{Analysis of reactions}

In solid-gas reactions, the solid phase is usually a granular medium through which the gaseous reactant circulates and reacts at the solid interface [14]. Due to the reactions occurring at a microscopic level, the solid material undergoes chemical and structural change as the reaction proceeds. Several reaction models are used in describing gas-solid reactions [15]. The unreacted shrinking core model is commonly used. In this model, the reaction product forms a solid layer that allows diffusion of reactant gas towards the interface between the product layer 
and unreacted core. A continuous reaction leads to the advancing of a reaction front, or equivalently, a shrinking core. The entire reaction kinetics involves three steps: transport and dissolution of the gas reactant at the solid surface, diffusion of the gas reactant through the product layer towards the unreacted core and finally chemical reaction of the gas with the solid reactant at the product-core interface [16].

Thermal analysis is employed to study the heterogeneous reactions. In (simultaneous) differential thermal analysis (DTA), the heat flow and, in thermogravimetric analysis (TGA), the mass change are measured while the material is heated at a constant the heating rate [17]. From the measured data, the kinetic triplet, which describes the conversion of a material $(\alpha)$ as a function of temperature $(T)$ and time $(t)$, is derived. The kinetic triplet parameters are the activation energy $E_{\mathrm{A}}$, the Arrhenius or frequency constant $A$ and the reaction model $f(\alpha)$ [18]. For nonisothermal experiments, the rate of transformation of any material is given by:

$\frac{\mathrm{d} \alpha}{\mathrm{d} T}=\frac{\mathrm{d} \alpha}{\mathrm{d} t} \cdot \frac{\mathrm{d} t}{\mathrm{~d} T}$

where the fraction converted at any time is given by:

$\alpha=\frac{m_{t}-m_{0}}{m_{\infty}-m_{0}}$

in which $m_{0}, m_{t}$ and $m_{\infty}$ denote the mass at time $t 0, t$ and $\infty$ (i.e. after full conversion), respectively. $\mathrm{d} T / \mathrm{d} t$ is the heating rate denoted as $\beta$, and $\mathrm{d} \alpha / \mathrm{d} t$ is the isothermal conversion rate and expressed as:

$\frac{\mathrm{d} \alpha}{\mathrm{d} t}=A e^{\frac{-E_{\mathrm{A}}}{R T}} f(\alpha)$

Combining Eqs. (1) and (3) leads to the nonisothermal conversion rate:

$\frac{\mathrm{d} \alpha}{\mathrm{d} T}=\frac{A}{\beta} e^{\frac{-E_{\mathrm{A}}}{R T}} f(\alpha)$

Integration results in the non-isothermal transformation rate law given by:

$g(\alpha)=\frac{A}{\beta} \int_{0}^{T} e^{\frac{-E_{A}}{R T}} \mathrm{~d} T$

This temperature integral has no analytical solution [17, 19], but is usually approximated by a series expansion or converted in an approximate form that can be integrated. A frequently used approximation is that by Senum and Yang [20]. Consider $x=E_{\mathrm{A}} /$ $R T$, then:

$$
\int_{0}^{T} e^{\frac{E_{A}}{R T}} \mathrm{~d} T=\frac{E_{\mathrm{A}}}{R} \int_{x}^{\infty} \frac{e^{-x}}{x^{2}} \mathrm{~d} x
$$

With $p(x)=\int^{\infty} \frac{e^{-x}}{x^{2}} \mathrm{~d} x$, Eq. (6) is approximated with the fourth ratiohal of Senum and Yang [20], i.e.

$p(x)=\frac{e^{-x}}{x}\left[\frac{x^{3}+18 x^{2}+86 x+96}{x^{4}+20 x^{3}+120 x^{2}+240 x+120}\right]$

Successively, the activation energy, the reaction model and finally the Arrhenius constant will be determined from non-isothermal experimental data. In the above analysis, the kinetic parameters are considered to be independent of temperature and fraction converted.

\section{Activation energy}

Regardless of the reaction order, the activation energy of the conversion reaction $E_{\mathrm{A}}$ can be obtained directly from non-isothermal TGA or DTA data using the so-called Kissinger method [21, 22]. If the temperature rises during the reaction, the reaction rate will rise to a maximum value, but return to zero as the reactant is exhausted. The maximum rate is associated with either a maximum mass change or heat evolution, which occurs at the peak temperature. Then, the governing equation for the determination of the activation energy reads:

$\ln \left(\frac{\beta}{T_{\mathrm{p}}^{2}}\right)+\frac{E_{\mathrm{A}}}{R T_{\mathrm{p}}}=C$

where $T_{\mathrm{p}}$ is the peak temperature, corresponding to the temperature at which the reaction rate is at maximum. Then, the highest heat flux or mass change rate is recorded. $R$ is the gas constant, and $C$ is a constant. Thus, the activation energy $\left(E_{\mathrm{A}}\right)$ is obtained by plotting $\ln \left(\beta / T_{\mathrm{p}}^{2}\right)$ versus $1 / T_{\mathrm{P}}$ for a series of measurements at different heating rates $\beta$.

\section{Reaction model}

The reaction model mathematically describes the conversion process of a material as a result of an occurring chemical or physical reaction. Different models have been derived for solid-state reactions [18], which comprises nucleation, geometrical contraction, diffusion and reaction-order models. To 
determine the appropriate model to analyse the experimental data, the so-called master curve plotting method is used. This method is based on the concept of generalized time $\theta$ [23], which is defined by Eq. (9) for isothermal or non-isothermal reactions, respectively, as:

$\theta=\int_{0}^{t} e^{\frac{-E_{\mathrm{A}}}{R T}} \mathrm{~d} t$ or $\theta=\frac{1}{\beta} \int_{0}^{T} e^{\frac{-E_{\mathrm{A}}}{R T}} \mathrm{~d} T$

$\boldsymbol{\theta}$ denotes the reaction time taken to attain a particular fraction converted at infinite temperature. Now, Eqs. (3) and (5) can be rewritten in terms of generalized time, respectively, as:

$\frac{\mathrm{d} \alpha}{\mathrm{d} \theta}=A f(\alpha)$

$g(\alpha)=A \theta$

As a reference point for the master curve plotting analysis, generally the level $\alpha=0.5$ is chosen and using Eq. (10) it can be derived that:

$\frac{\mathrm{d} \alpha / \mathrm{d} \theta}{(\mathrm{d} \alpha / \mathrm{d} \theta)_{\alpha=0.5}}=\frac{f(\alpha)}{f(0.5)}$

From the experimentally determined conversion rate, with respect to the generalized time, as a function of fraction converted, $f(\alpha) / f(0.5)$ versus $\alpha$ can be obtained, since

$\frac{\mathrm{d} \alpha}{\mathrm{d} \theta}=\frac{\mathrm{d} \alpha}{\mathrm{d} t} \exp \left(\frac{E_{A}}{R T}\right)$ or $\frac{\mathrm{d} \alpha}{\mathrm{d} \theta}=\beta \frac{\mathrm{d} \alpha}{\mathrm{d} T} \exp \left(\frac{E_{\mathrm{A}}}{R T}\right)$

By comparing the experimental result with theoretical reaction models [23], the reaction model that best fits the measured data can be determined. From this, the key reaction mechanisms can be determined and this knowledge can be used to optimise the material performance.

\section{Arrhenius constant}

The last of the kinetic triplet, i.e. the pre-exponential factor $(A)$, can be evaluated from Eq. (11), once the reaction model is determined; cf. "Reaction model" section. The generalized time $\boldsymbol{\theta}$ for non-isothermal reactions [Eq. (9)] resembles Eq. (6) and hence can be written as:

$\theta=\frac{E_{\mathrm{A}}}{\beta R} p(x)$

while $p(x)$ is approximated using Eq. (7).

\section{Experimental procedure}

The five TiC powders used in this study are all commercially available, and their main features are summarized in Table 1. The first and second powders, having an average particle size of 140 and $48 \mu \mathrm{m}$, respectively, were obtained by sieving a TiC powder with a broad size distribution (Goodfellow, UK; product number TI546030). The third TiC powder with an average particle size of $5 \mu \mathrm{m}$ was supplied by Alfa Aesar, Germany (product number TiC 40178). The fourth $\mathrm{TiC}$ powder with an average particle size of $0.8 \mu \mathrm{m}$ was supplied by American Elements, USA (product number TI-C-03M-NP.800NS). Finally, the fifth $\mathrm{TiC}$ powder with an average particle size of $50 \mathrm{~nm}$ was supplied by Chempur, Germany (Product number CFF-NP059).

The purity of the powders studied was determined with X-ray fluorescence spectroscopy (XRF) using an Axios Max WD-XRF instrument (PANanalytical, The Netherlands), and the data were evaluated with SuperQ5.0i/Omnian software. The size distribution of the TiC particles was determined by laser diffraction using the Microtrac 3500 (Microtrac Inc., USA) equipped with a tri-laser diode detection system. The particle morphology of each TiC powder was recorded with scanning electron microscopy (SEM) using a JSM 6500F (JEOL, Japan). The instrument used was equipped with an energy-dispersive spectrometer (EDS; Ultra Dry $30 \mathrm{~mm}^{2}$ detector, Thermo Fisher Scientific, USA) for X-ray microanalysis (XMA).

The oxidation kinetics of the TiC powders was studied non-isothermally using simultaneous thermogravimetric (TG) and differential thermal analysis (DTA) using a high-performance symmetrical double furnace balance (TAG 16/18, Setaram, France). $20 \pm 1 \mathrm{mg}$ of the powder was put into a $100-\mu \mathrm{L} \mathrm{Al}_{2} \mathrm{O}_{3}$ crucible and placed onto a TG-DTA rod with an S-type thermocouple. A similar rod but without crucibles was placed as a counterweight on the other side of the balance to aid automatic correction of buoyancy effects. Then, the dual furnaces were heated up from room temperature to $1200{ }^{\circ} \mathrm{C}$ with various heating rates (between 1 and $10{ }^{\circ} \mathrm{C} \mathrm{min}{ }^{-1}$ ). In each measurement, both furnaces were purged with dry synthetic air $\quad\left(\mathrm{N}_{2}+20 \mathrm{vol} \% \quad \mathrm{O}_{2}\right.$ and $\mathrm{H}_{2} \mathrm{O}$ $<10 \mathrm{ppm}$ ) at a total flow rate of $50 \mathrm{sccm}$. The evolved gas at the sample location was collected and analysed with an Omnistar GSD 301 system having a quadrupole mass spectrometer (QMS 200 M3 from Pfeiffer 
Table 1 Size and composition of TiC powders with $D_{50}$ as the average particle size and $D_{10}$ and $D_{90}$ as the particle size at 10 and $90 \%$ cut-off, respectively, in the size distribution

\begin{tabular}{|c|c|c|c|c|c|}
\hline Powder & $D_{50}(\mu \mathrm{m})$ & $D_{10}-D_{90}(\mu \mathrm{m})$ & $\mathrm{TiC}(\mathrm{wt} \%)$ & \multicolumn{2}{|c|}{ Main impurities (wt $\%)$} \\
\hline 1 & 140 & $100-150$ & 99.75 & $\begin{array}{l}\mathrm{Fe} \\
\mathrm{Si}\end{array}$ & $\begin{array}{l}0.089 \\
0.04\end{array}$ \\
\hline 2 & 48 & $40-50$ & 99.75 & $\begin{array}{l}\mathrm{Fe} \\
\mathrm{Si}\end{array}$ & $\begin{array}{l}0.089 \\
0.04\end{array}$ \\
\hline 3 & 5 & $2-15$ & 98.17 & $\begin{array}{l}\mathrm{WC} \\
\mathrm{Fe}\end{array}$ & $\begin{array}{l}1.552 \\
0.105\end{array}$ \\
\hline 4 & 0.8 & $0.6-1$ & 90.8 & $\begin{array}{l}\mathrm{W} \\
\mathrm{Co}\end{array}$ & $\begin{array}{l}7.25 \\
0.68\end{array}$ \\
\hline 5 & 0.05 & $0.04-0.07$ & 99.966 & $\begin{array}{l}\mathrm{Si} \\
\mathrm{Cl}\end{array}$ & $\begin{array}{l}0.017 \\
0.008\end{array}$ \\
\hline
\end{tabular}

Omnistar, Germany) in order to observe the evolution of $\mathrm{CO}_{2}$.

The thermal analysis system used was equipped with Calisto acquisition and processing software (v1.43 DB v1.44, Setaram, France) which records both the furnace and the sample temperature. For accurate results, the temperature measured by the thermocouples at the sample position is used for the analysis as this represents the true sample temperature. Prior to admitting the gases to the furnaces, each gas, i.e. Ar, $\mathrm{N}_{2}$ and $\mathrm{O}_{2}$ (all with $5 \mathrm{~N}$ vol\% purity), was filtered to remove any residual hydrocarbons, moisture and oxygen (for $\mathrm{N}_{2}$ and Ar). The Accosorb $(<10 \mathrm{ppb}$ hydrocarbons), Hydrosorb $\left(<10 \mathrm{ppb} \quad \mathrm{H}_{2} \mathrm{O}\right)$ and Oxysorb $\left(<5 \mathrm{ppb} \mathrm{O}_{2}\right)$ filters (Messer Griesheim, Germany) were used. The flow of each gas was regulated and monitored with LabView (version 12, National Instruments, USA) using calibrated mass flow controllers (Bronkhorst, The Netherlands).

The oxidation products and lattice parameter were identified and measured by X-ray diffraction using a Bruker D8 Advance diffractometer (Bruker, Germany) equipped with a graphite monochromator. Diffractograms were recorded with $\mathrm{Co} \mathrm{K} \alpha$ radiation in the $2 \theta$ range of $10^{\circ}-130^{\circ}$ and a step size of $0.034^{\circ}$. The data were processed with the Diffrac EVA 4.1 Bruker software.

\section{Results}

\section{TiC powder oxidation}

Oxidation of the $5 \mu \mathrm{m}$ powder was studied first by heating from room temperature to $1200{ }^{\circ} \mathrm{C}$ at $5{ }^{\circ} \mathrm{C} \mathrm{min}^{-1}$ in air, and the heat flow and the conversion curves are presented in Fig. 1. Transformation

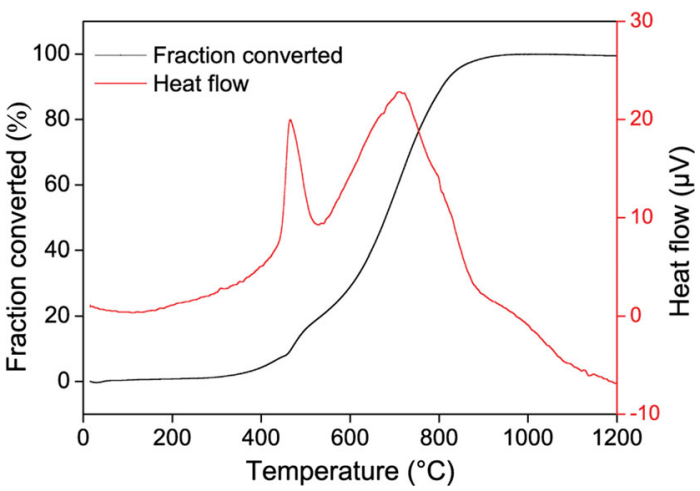

Figure 1 Heat flow and mass gained signals for the $5 \mu \mathrm{m}$ powder oxidized at $5{ }^{\circ} \mathrm{C} \min ^{-1}$ in dry synthetic air.

starts just before $400{ }^{\circ} \mathrm{C}$ and ends around $900{ }^{\circ} \mathrm{C}$ via two exothermic peaks at about 470 and $710{ }^{\circ} \mathrm{C}$. Therefore, to fully describe the oxidation of $\mathrm{TiC}$, two separate experiments are performed on the same powder under the same conditions till the end of each peak (i.e. till 530 and $900{ }^{\circ} \mathrm{C}$ ) and the oxidation products analysed.

XRD confirms that part of the TiC powder is converted into anatase and rutile in the ratio of about $3: 2$ in the first peak and the remaining $\mathrm{TiC}$, oxycarbide and anatase are converted into rutile in the second peak. The morphology of the $5 \mu \mathrm{m} \mathrm{TiC} \mathrm{powder} \mathrm{at}$ different stages of non-isothermal oxidation with a heating rate of $5{ }^{\circ} \mathrm{C} \mathrm{min}{ }^{-1}$ in dry synthetic air is shown in Fig. 2. The starting $\mathrm{TiC}$ particles are irregularly shaped with sharp edges; see Fig. 2a. After oxidation up to $530{ }^{\circ} \mathrm{C}$, some anatase was formed at the surfaces; see Fig. 2b. Finally, after full transformation into rutile the particles became more rounded at the edges as shown in Fig. 2c.

As the experiment in Fig. 1 proceeded, the gases evolved were collected and analysed. $\mathrm{CO}_{2}$ was the only gas detected, and the recorded pressure is 

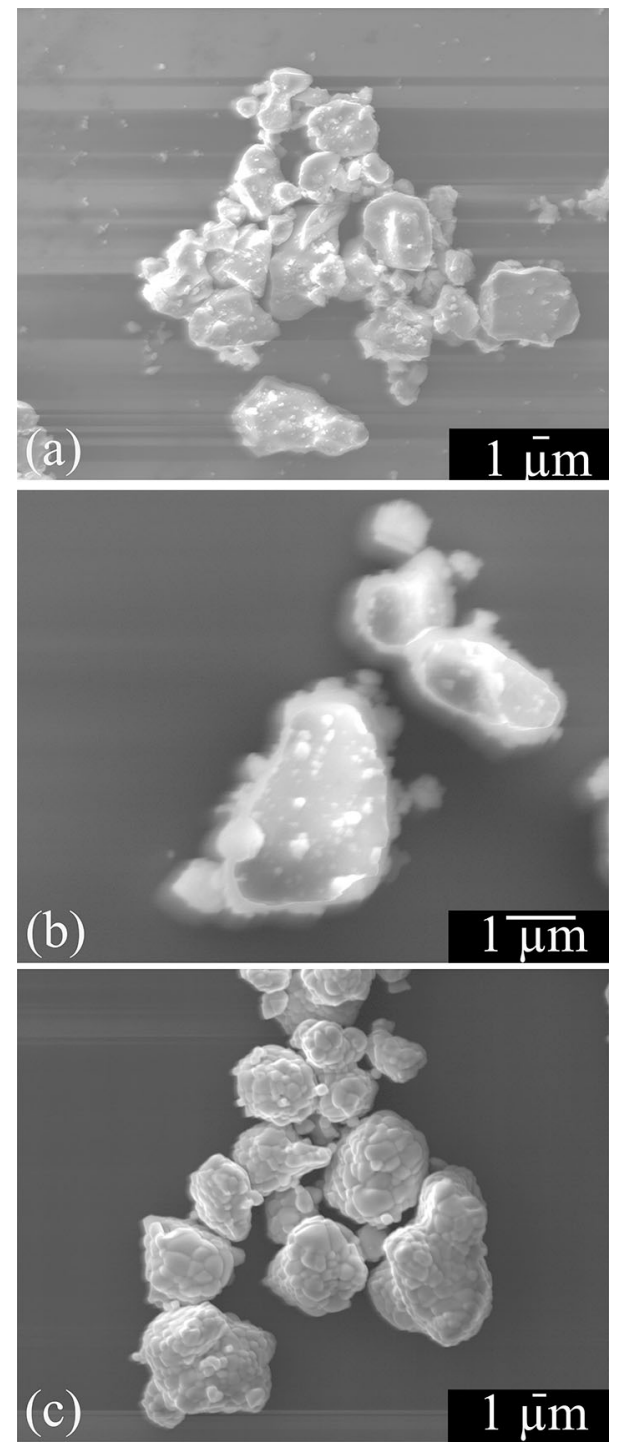

Figure 2 SEM images of $\mathrm{TiC}$ powder with an average particle size of $5 \mu \mathrm{m}$ after non-isothermal oxidation in synthetic dry air with a heating rate of $5{ }^{\circ} \mathrm{C} \mathrm{min}^{-1}$; cf. Fig. 1. a The raw powder, b oxidized up to $530{ }^{\circ} \mathrm{C}$ (formation of anatase) and c oxidised up to $1200{ }^{\circ} \mathrm{C}$ (fully transformed into rutile).

presented in Fig. 3. It is noticeable that the removal of $\mathrm{C}$ via $\mathrm{CO}_{2}$ release and the precipitation of $\mathrm{TiO}_{2}$ occur simultaneously as the heat flow peaks in Fig. 1 and the $\mathrm{CO}_{2}$ signal in Fig. 3 closely overlap at the same temperatures.

A zoom in at about $320{ }^{\circ} \mathrm{C}$ of Fig. 3 shows a small peak (inset of Fig. 3) which is not immediately identified in the heat flow signal in Fig. 1. Hence, the mass change signal in Fig. 1 is further differentiated in Fig. 4, and then a kink coinciding with the peak at $320{ }^{\circ} \mathrm{C}$ in Fig. 3 is identified.

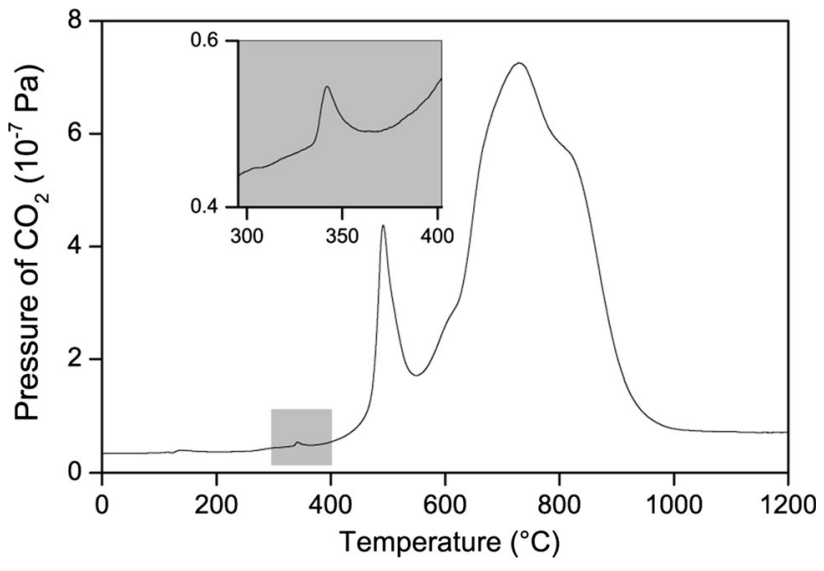

Figure 3 Evolution of $\mathrm{CO}_{2}$ during oxidation of $\mathrm{TiC}$ powder with average particle size of $5 \mu \mathrm{m}$ in dry synthetic air recorded with $5{ }^{\circ} \mathrm{C} \mathrm{min}{ }^{-1}$. Insert confirms the release of $\mathrm{CO}_{2}$ during oxycarbide formation.

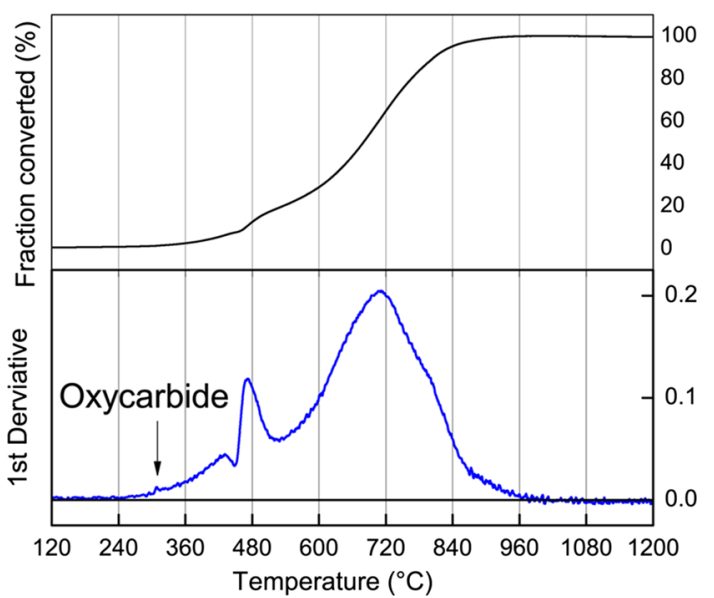

Figure 4 Differentiated mass gain signal $(\mathrm{d} \Delta m / \mathrm{d} t)$ of $5 \mu \mathrm{m} \mathrm{TiC}$ powder recorded with $5{ }^{\circ} \mathrm{C} \mathrm{min}^{-1}$ when oxidizing in dry synthetic air.

Another experiment using a fresh sample was run under the same conditions until $360^{\circ} \mathrm{C}$ to determine the reaction occurring around $320^{\circ} \mathrm{C}$. No oxide was identified by XRD after controlled cooling of the reaction product obtained although the sample weight had increased and $\mathrm{CO}_{2}$ had been released. The combination of observations shows that the lowtemperature peak is due to the substitution of atomic oxygen at carbon sites of the TiC lattice [12], leading to the formation of $\mathrm{TiC}_{y} \mathrm{O}_{1-y}$ which is evidenced by the reduction in the lattice parameter of $\mathrm{TiC}$ [24]. In this specific case, the lattice parameter of the starting material reduced from $4.3275 \pm 0.0001$ to $4.3260 \pm 0.00005 \AA$ after heating up to $360{ }^{\circ} \mathrm{C}$. This oxycarbide phase exists throughout the oxidation 
process $[12,25]$ and thus may act as a precursor for the formation of anatase and rutile.

The oxidation of the $5 \mu \mathrm{m}$ powder can be summarized as follows. A first oxycarbide formation stage takes place over the interval from about $300-360{ }^{\circ} \mathrm{C}$. A second oxidation stage which leads to the formation of both rutile and anatase sets in after the first reaction and peaks around $470{ }^{\circ} \mathrm{C}$ and ends just before $530{ }^{\circ} \mathrm{C}$; see Fig. 1. (This stage is hereafter referred to as the anatase formation stage.) Although a single peak in the heat flow signal characterizes this step, the mass change signal clearly shows two consecutive stages. The first of these two stages starts from 430 to $470{ }^{\circ} \mathrm{C}$, and this proceeds relatively fast showing a very steep conversion versus temperature curve. The second stage which proceeds at a relatively slower rate continues from $470{ }^{\circ} \mathrm{C}$ and ends at about $520^{\circ} \mathrm{C}$. A last oxidation stage starts from $530{ }^{\circ} \mathrm{C}$ and ends at around $960{ }^{\circ} \mathrm{C}$, where the remaining $\mathrm{TiC}$, oxycarbide and anatase are converted into rutile. A similar reaction scheme was observed and reported earlier by [12] when studying the oxidation behaviour of $\mathrm{TiC}$ powder at various oxygen partial pressures. However, in that study the second stage was split up into the formation of anatase and rutile; in addition, it was mentioned that these two stages may overlap and cannot be clearly distinguished from each other.

To continue, the other powders were all heated at $5{ }^{\circ} \mathrm{C} \mathrm{min}^{-1}$ in air in separate experiments. The results are presented in Fig. 5. As observed for the $5 \mu \mathrm{m}$ powder, multiple peaks are identified for the different particle sizes. The stages of oxidation were resolved by running separate experiments up to each identified peak in the heat flow or the differentiated mass change signal, and then the products were analysed by XRD and/or XMA.

For the coarsest powders having an average particle size of 140 and $48 \mu \mathrm{m}$, only the peaks pertaining to the formation of anatase and rutile can be identified in the heat flow and mass change signals (see Fig. 5a, b, respectively). The stage of oxycarbide formation appears to be overshadowed. For both powders, the peak occurring between 400 and $600{ }^{\circ} \mathrm{C}$ corresponds to the formation of anatase. The formation of rutile sets in at $800{ }^{\circ} \mathrm{C}$ and ends at $1195{ }^{\circ} \mathrm{C}$ for
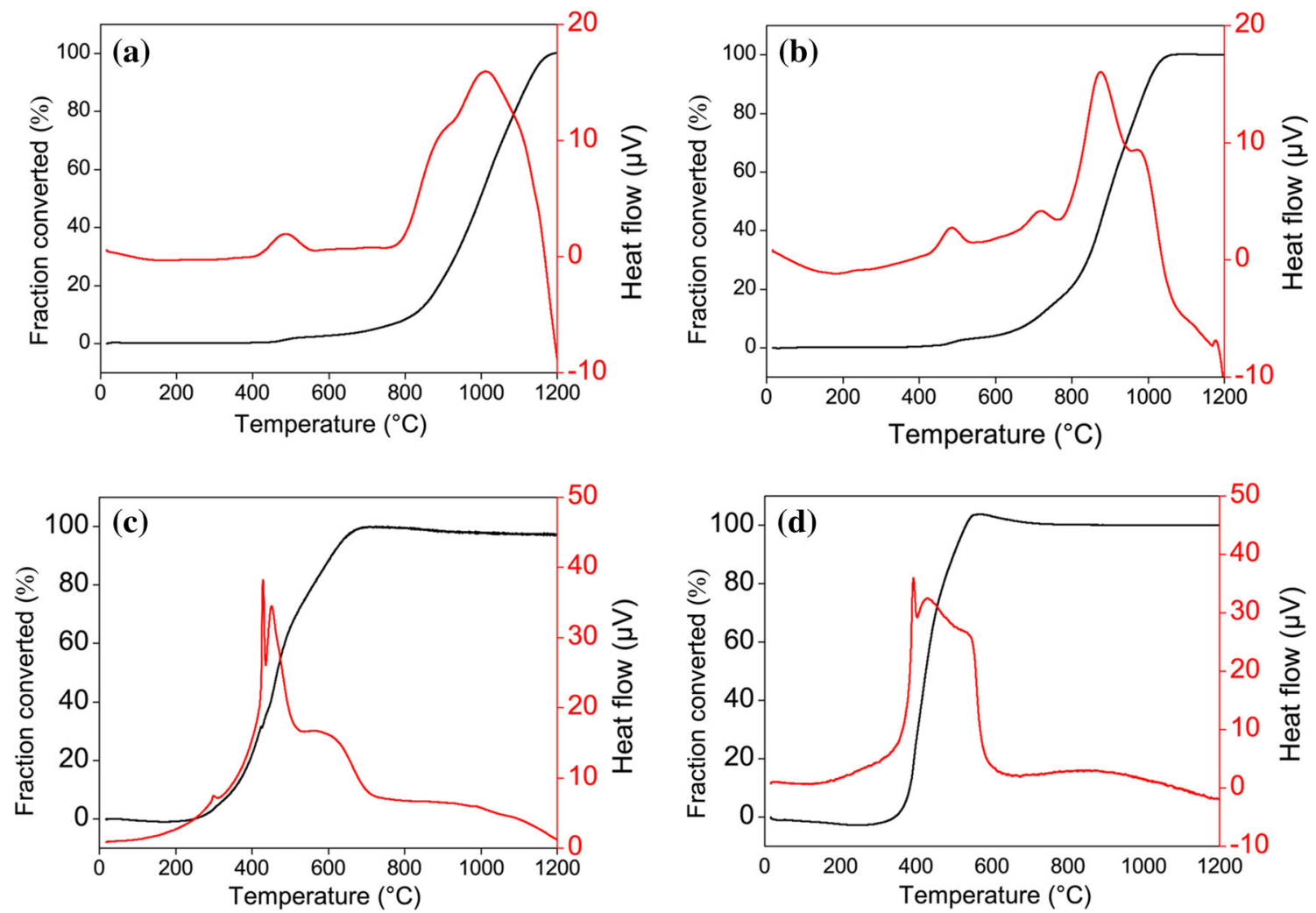

Figure 5 Heat flow and mass change in terms of converted fraction TiC (in \%) as a function of temperature recorded at $5{ }^{\circ} \mathrm{C}$ min ${ }^{-1}$ in dry synthetic air of TiC powders with average size of: a $140 \mu \mathrm{m}, \mathbf{b} 48 \mu \mathrm{m}, \mathbf{c} 0.8 \mu \mathrm{m}$ and $\mathbf{d} 0.05 \mu \mathrm{m}$. 
the $140 \mu \mathrm{m}$ powder, and for the $48 \mu \mathrm{m}$ powder it starts from $700{ }^{\circ} \mathrm{C}$ and ends around $1050{ }^{\circ} \mathrm{C}$. It is noteworthy that the transformation into rutile of both coarse powders occurs via multiple steps while the mass gain signal for this range reflects a single peak event (i.e. a non-changing slope).

For the $0.8 \mu \mathrm{m} \mathrm{TiC}$ powder, all three stages observed for the $5 \mu \mathrm{m}$ powder can be identified in the heat flow signal. The formation of the oxycarbide is shown in Fig. $5 \mathrm{c}$ peaking at about $310^{\circ} \mathrm{C}$, as well as in the differentiated mass gain signals shown in Fig. 6. Anatase is formed in the sharp peak around $420{ }^{\circ} \mathrm{C}$ followed immediately by conversion into rutile which also occurs via two peaks.

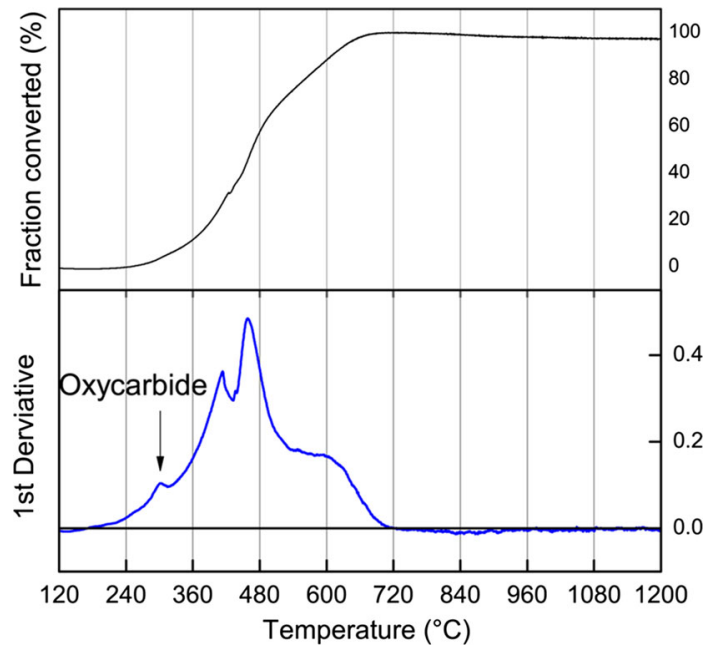

Figure 6 Differentiated mass gain signal $(\mathrm{d} \Delta m / \mathrm{d} t)$ of $0.8 \mu \mathrm{m} \mathrm{TiC}$ powder recorded with $5{ }^{\circ} \mathrm{C} \mathrm{min}^{-1}$ in dry synthetic air.

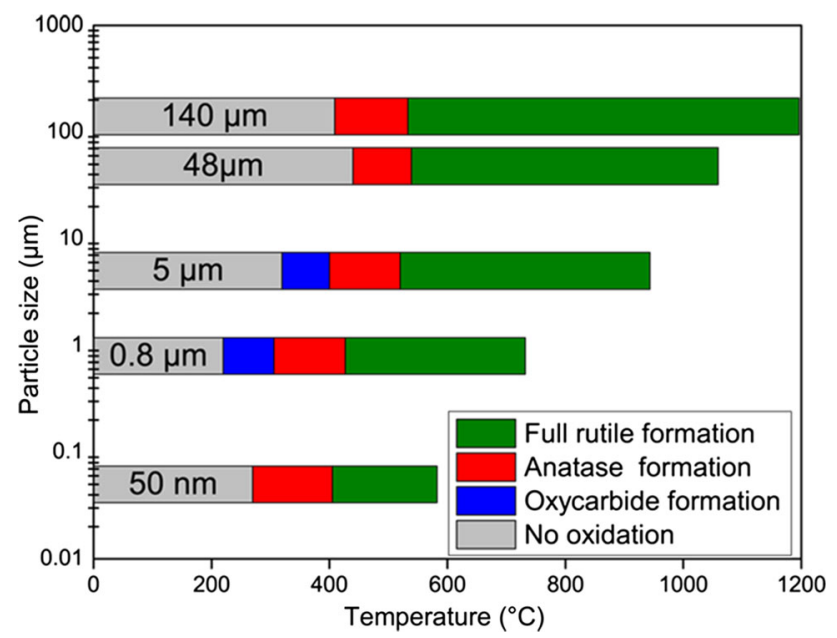

Figure 7 Chart showing the various stages of oxidation in dry synthetic air of $\mathrm{TiC}$ particles with different average particle sizes.
Figure 8 Heat flow and mass change in terms of converted fraction $\mathrm{TiC}$ (in \%) as a function of temperature recorded at different heating rates in dry synthetic air of $\mathrm{TiC}$ powders with average particle size of: a, b $140 \mu \mathrm{m}, \mathbf{c}, \mathbf{d} 48 \mu \mathrm{m}, \mathbf{e}, \mathbf{f} 5 \mu \mathrm{m}, \mathbf{g}$, h $0.8 \mu \mathrm{m}$ and $\mathbf{i}, \mathbf{j} 0.05 \mu \mathrm{m}$.

For the nano-powder the mechanism somewhat reverses to that of the coarser powders as no trace of the oxycarbide formation can be detected. A peak corresponding with the formation of anatase can be identified at $400{ }^{\circ} \mathrm{C}$, and two peaks associated with the formation of rutile can be identified at about 430 and $550{ }^{\circ} \mathrm{C}$, respectively, in Fig. $5 \mathrm{~d}$. The various stages of oxidation, as identified for the different particle sizes, are summarized as a function of temperature in Fig. 7. Depending on the particle size, some stages may overlap or is overshadowed and hence not always clearly resolved in the mass gain and heat flow signals as a function of temperature.

\section{Effect of heating rate on oxidation}

As the heating rate is increased, the amount of $\mathrm{TiC}$ transformed into anatase is reduced. For example, for the $140 \mu \mathrm{m}$ powder the amount of $\mathrm{TiC}$ transformed decreases from 4 to $1 \%$ as heating rate is increased from 1 to $10{ }^{\circ} \mathrm{C} \mathrm{min}{ }^{-1}$. Similarly, there was a decrease of about $5-1.5 \%$ and $40-15 \%$ for the 48 and $5 \mu \mathrm{m}$ powders, respectively, during the same stage, see Fig. 8 .

For the same amount of powder, the surface area exposed to oxygen increases when the $\mathrm{TiC}$ particle size is reduced. Then, the conversion of $\mathrm{TiC}$ into $\mathrm{TiO}_{2}$ is enhanced. This is evident from the heat flow signal recorded with the same heating rate, which increases for smaller particles. For example, the formation of rutile when oxidizing $5 \mu \mathrm{m} \mathrm{TiC} \mathrm{powder} \mathrm{at}$ $10{ }^{\circ} \mathrm{C}$ min $^{-1}$ corresponds with about $45 \mu \mathrm{V}$ of heat evolved, while under the same conditions $140 \mu \mathrm{m}$ TiC powder results in about $28 \mu \mathrm{V}$ of heat evolved; cf. Fig. $8 \mathrm{a}$, e. Since the oxidation of TiC powder is faster when the particle size is smaller, the final temperature for full conversion of $\mathrm{TiC}$ powder into $\mathrm{TiO}_{2}$ (rutile) during non-isothermal oxidation (at the same heating rate) decreases with particle size; see Fig. 8 .

A final observable trend is that the stages of oxidation are well separated from each other (in both the heat flow and the fraction converted signals) at larger particle sizes. However, as the particle size is reduced, these stages become indistinguishable in the 

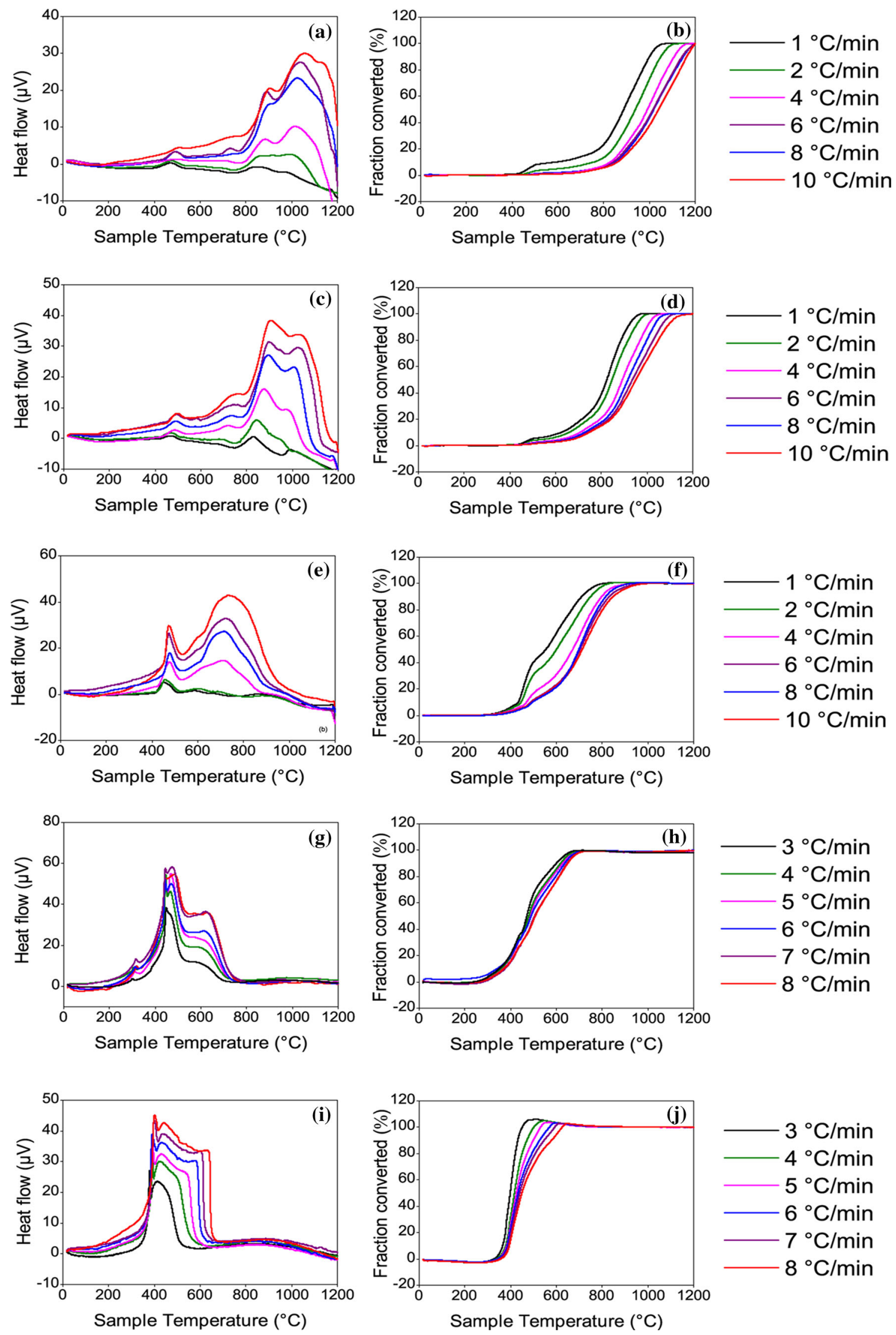
fraction converted plots especially for the $50 \mathrm{~nm}$ powder.

\section{Evaluation of the activation energy}

The activation energy for oxidation of the different TiC powders is determined using Eq. (8). As more than one peak occurs during the transformation reaction, the peak temperature $\left(T_{p}\right)$ is defined as the highest point in the differentiated mass gain signal. The results for the various $\mathrm{TiC}$ powders are presented in Fig. 9. With decreasing particle size, the lines for the maximum conversion of $\mathrm{TiC}$ into $\mathrm{TiO}_{2}$ shifts to lower temperatures, and this defines the temperature window where a particle is activated. The slope of these lines corresponds to the activation energy of the reaction, and the figure clearly shows it decreases with decreasing particle size.

The values of the activation energy $E_{\mathrm{A}}$ as a function of the TiC particle size are presented in Table 2. It is observed that $E_{\mathrm{A}}$ significantly decreases with decrease in particle size for submicron and nanosized particles and is more or less constant for particle sizes $>5 \mu \mathrm{m}$. The activation energies determined here are comparable to those determined in other studies (e.g. [11, 25]), i.e. 192 and $245 \mathrm{~kJ} \mathrm{~mol}^{-1}$. The (non-significant) difference may arise from the size of the TiC particles and the limited temperature window of the isothermal experiments used in the present analysis.

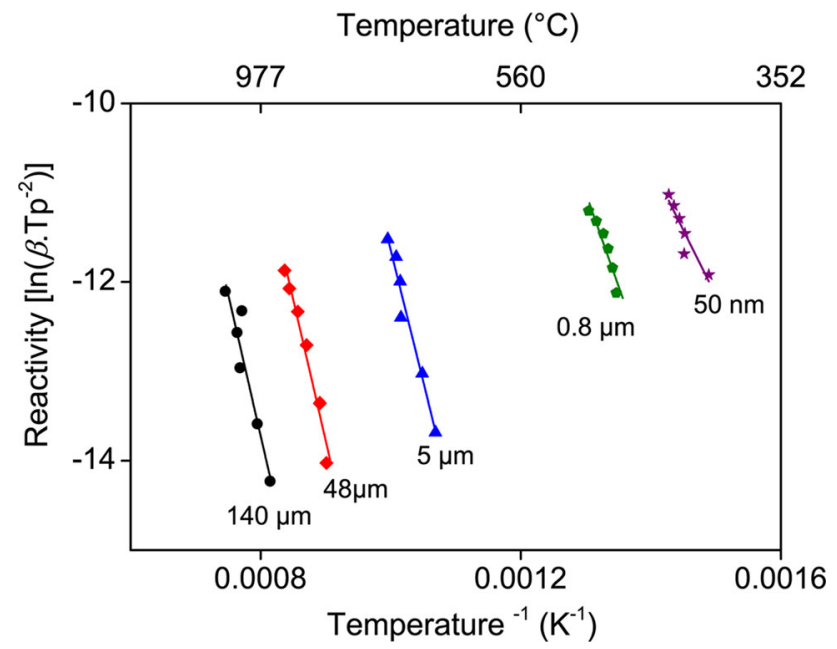

Figure 9 Kissinger plot for estimating the activation energies size for the oxidation of $\mathrm{TiC}$ powder with different particles sizes in dry synthetic air; see Eq. (8).
Table 2 Activation energies as determined for oxidation of TiC powders with different particle sizes

\begin{tabular}{ll}
\hline Size $(\mu \mathrm{m})$ & $E_{\mathrm{A}}\left(\mathrm{kJ} \mathrm{mol}^{-1}\right)$ \\
\hline 140 & $263 \pm 42$ \\
48 & $262 \pm 23$ \\
5 & $244 \pm 24$ \\
0.8 & $172 \pm 27$ \\
0.05 & $122 \pm 24$ \\
\hline
\end{tabular}

Effects of particle size on the activation energy have been reported for other materials as well $[26,27]$. It can be conceived that when the surface-tovolume ratio increases the activation energy decreases, since the atoms at the surface have fewer bonds and neighbouring atoms and thus need less energy to transfer into oxide [28].

Hence, the reduction of the bulk activation energy, $E_{\mathrm{A}}^{\text {bulk }}$, can be related to the surface energy $\sigma$ according to [29]:

$E_{\mathrm{A}}=E_{\mathrm{A}}^{\mathrm{bulk}}-\frac{6 \sigma V_{\mathrm{m}}}{d}$

in which $V_{\mathrm{m}}$ is the molar volume and $d$ the particle size. For TiC the surface energy equals $2.73 \mathrm{~J} \mathrm{~m}^{-2}$ [30] and the molar volume $12.18 \mathrm{~cm}^{3} \mathrm{~mol}^{-1}$ [31]. From Fig. 10, the observed reduction in the activation energy for submicron or nano-sized particles is due to surface defects (like: dislocations, grain boundaries, steps and kinks, roughness), of which their number increases with surface area (i.e. with $d^{-2}$ ) [32]. These surface defects promote the nucleation and growth of the oxide.

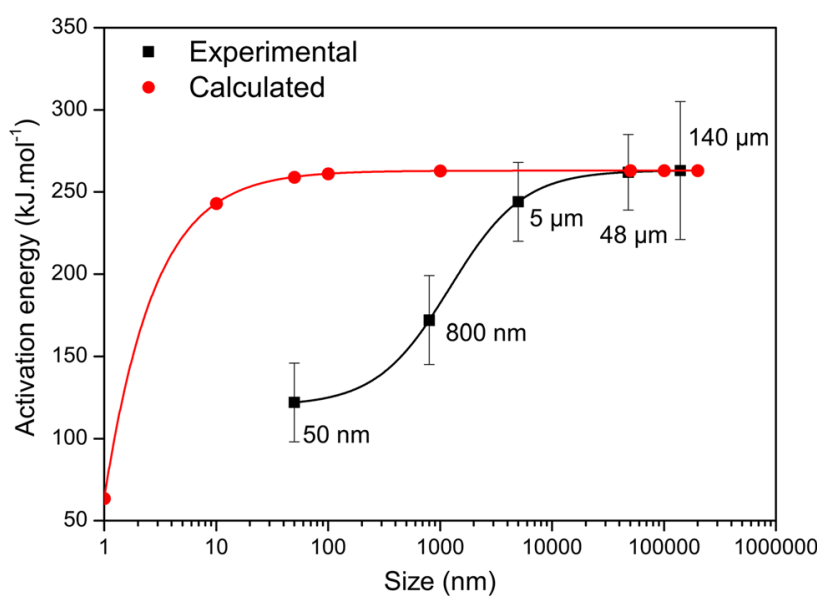

Figure 10 Activation energy as a function of particle size for the oxidation of TiC powder in dry synthetic air. The calculated values pertain to the effect of surface-to-volume ratio; see Eq. (15). 
Figure 11 Master plots of theoretical models and experimental data of $\mathrm{TiC}$ powders with average size of: a $140 \mu \mathrm{m}$, b $48 \mu \mathrm{m}$, c $5 \mu \mathrm{m}$, d $0.8 \mu \mathrm{m}$ and e $0.05 \mu \mathrm{m}$.
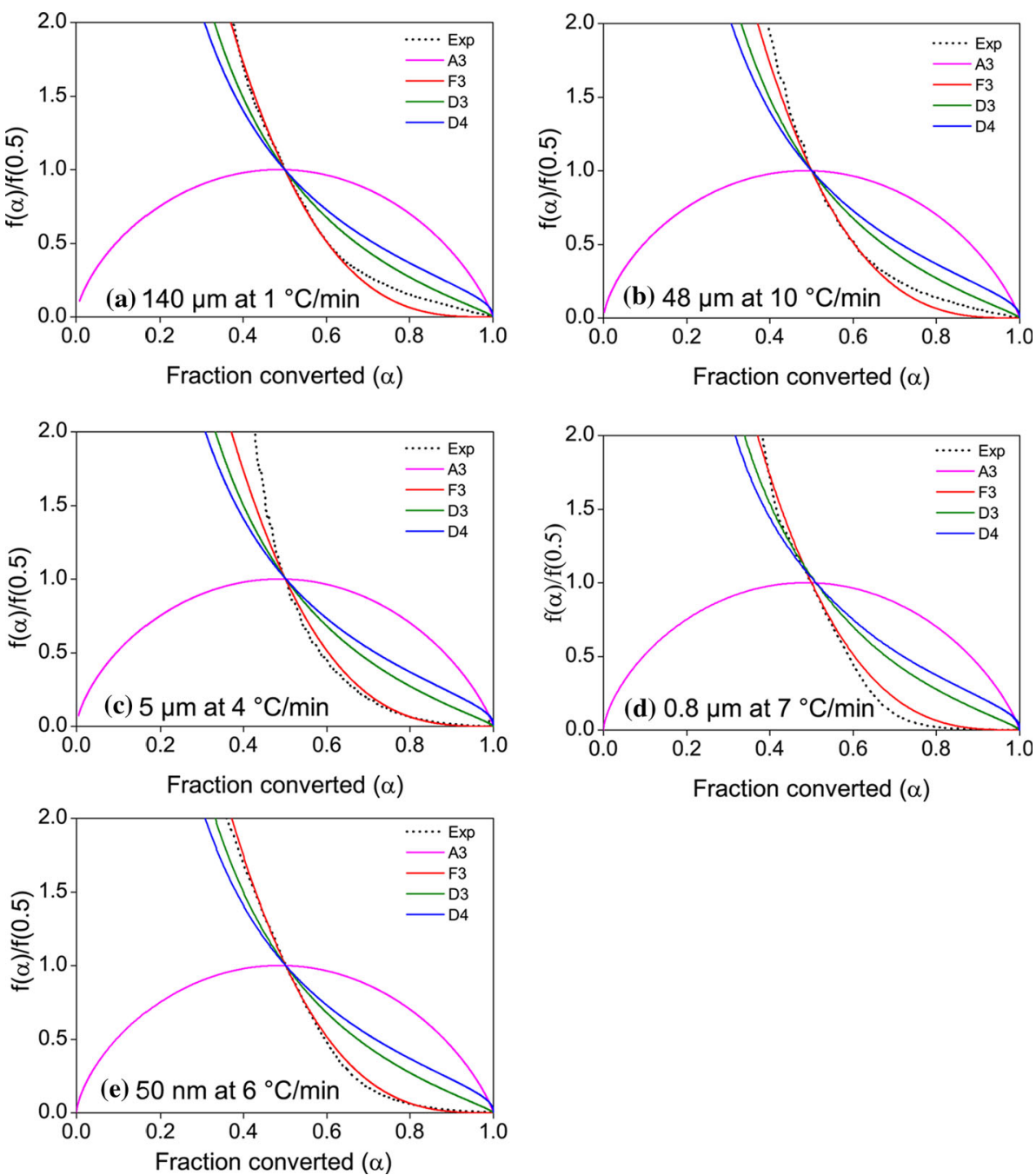

Fraction converted $(\alpha)$
Hence, the activation energy as a function of particle size is presented in Fig. 10 and the relationship can be best described with Eq. (16).

$E_{\mathrm{A}}=263+\left(\frac{120-263}{\left(1+\left(\frac{d}{1220}\right)^{1.325}\right)}\right)$

where $E_{\mathrm{A}}$ is the activation energy in $\mathrm{kJ} \mathrm{mol}^{-1}$ and $d$ is the particle size in $\mathrm{nm}$.

\section{Reaction model for TiC oxidation}

Out of the many reaction models [18], the nonisothermal plots of the rate of conversion with temperature pre-empt that the oxidation of $\mathrm{TiC}$ may be either an Avrami-Erofeyev, diffusion, or an order reaction model. Hence, the experimental data are compared with the Avrami-Erofeyev (A3), 3D diffusion Jander (D3), Ginstling-Brounshtein (D4) and the third-order (F3) reaction models using the master curve plotting method [23]; see "Reaction model" section. To ascertain the validity of the identified model, master plots are made for all the powders at different heating rates, see Fig. 11. It is seen that for different heating rates the experimental data closely resemble the F3 (third-order reaction model) more than any other model. The integral and the differential form of the third-order reaction model is, respectively, defined as:

$$
\begin{aligned}
& g(\alpha)=(1 / 2)\left[(1-\alpha)^{-2}-1\right] \\
& f(\alpha)=(1-\alpha)^{3}
\end{aligned}
$$

The rate-determining step in the oxidation of $\mathrm{TiC}$ is the diffusion of oxygen from the gaseous phase through the formed oxide layers and the opposite 
Table 3 Evaluated preexponential factors $(A)$ for $\mathrm{TiC}$ powders oxidized in dry synthetic air

\begin{tabular}{lr}
\hline Size $(\mu \mathrm{m})$ & \multicolumn{1}{c}{$A\left(\mathrm{~s}^{-1}\right)$} \\
\hline 140 & $3.3 \times 10^{10}$ \\
48 & $5 \times 10^{10}$ \\
5 & $100 \times 10^{10}$ \\
0.8 & $8.3 \times 10^{10}$ \\
0.05 & $1 \times 10^{8}$ \\
\hline
\end{tabular}

diffusion of titanium and carbon from the material into the scale.

\section{The Arrhenius pre-exponential factor}

The last of the kinetic triplet, i.e. the pre-exponential factor $(A)$, is evaluated from the integral form of the kinetic rate equation given in Eq. (11) combined with Eq. (17). The generalized time Eq. (9) is determined at every temperature from 25 to $1200{ }^{\circ} \mathrm{C}$ using
Eq. (14), the applied heating rate and the estimated $E_{\mathrm{A}}$. A linear fitting of Eq. (11) is made for the range of $\alpha$ pertaining to the third oxidation stage (i.e. transformation into rutile) to find the constant $A$. The calculated pre-exponential factors, as shown in Table 3, are relatively constant with the same order of magnitude. However, it significantly decreases for the nanometre-sized particles [33, 34]. As the particle size decreases, the partial molar surface enthalpy and the partial molar surface entropy increase, leading to the decrease in the apparent activation energy and the pre-exponential factor [29, 35]. There is no simple explanation for the high value of the Arrhenius parameter for the $5 \mu \mathrm{m}$ particle, other than undetected impurities or structural defects.

Finally, the conversion $\alpha$ of $\mathrm{TiC}$ into $\mathrm{TiO}_{2}$ by oxidation in air can be expressed as a function of temperature and time for each particle size by:
Figure 12 Comparing the fraction converted $(\alpha)$ for the experimental data and the calculated results of $\mathrm{TiC}$ powders in dry synthetic air.
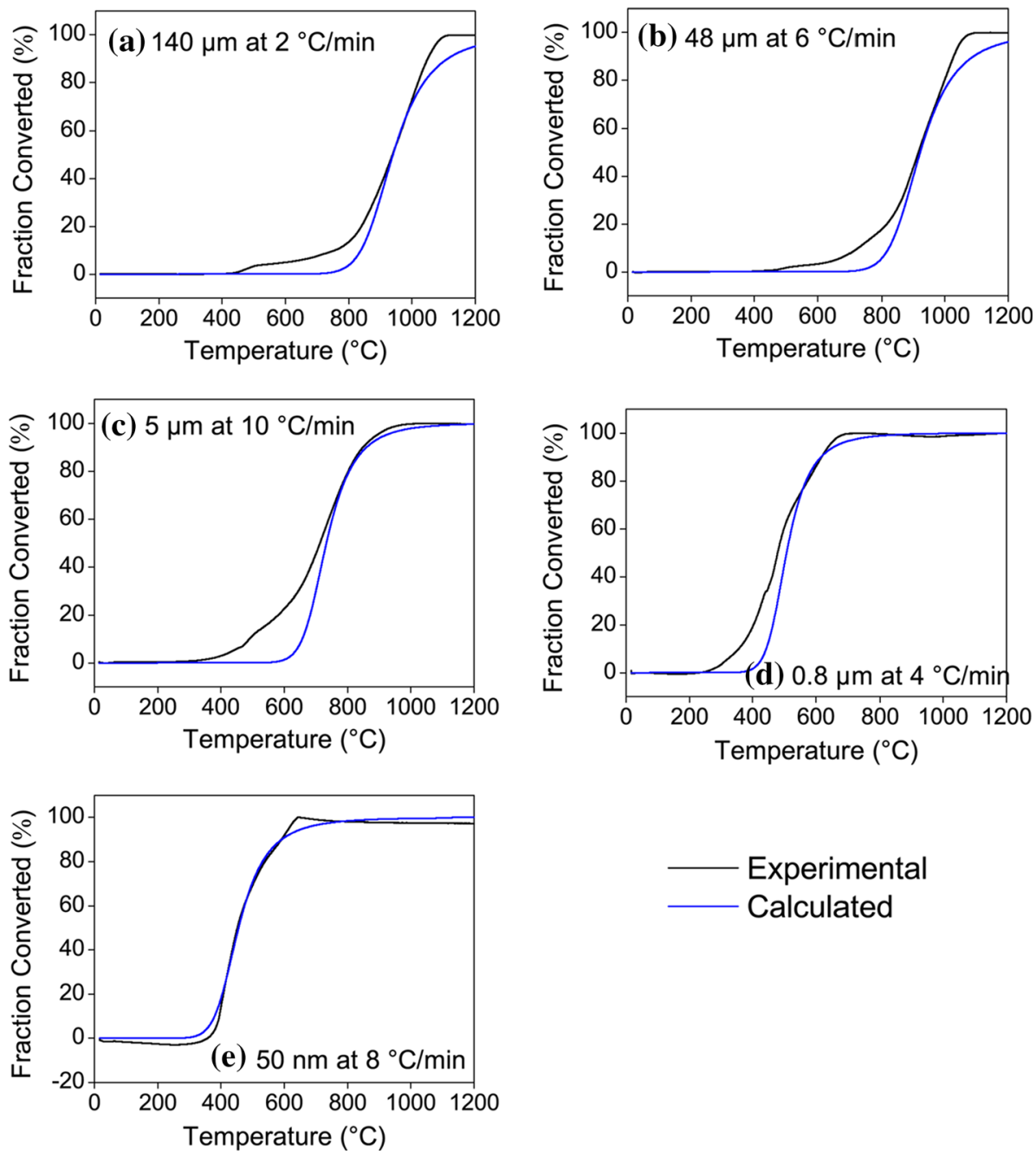
$\alpha=1-\left[(2 A \theta+1)^{(-1 / 2)}\right]$

with $\theta$ calculated using Eq. (14). It can be seen in Fig. 12 that at higher temperatures the calculated results fit well with the experimental results with a slight deviation at lower temperatures. This deviation is associated with initial stages of oxidation which corresponds to the formation of the oxycarbides and/ or anatase.

\section{Conclusions}

Oxidation of $\mathrm{TiC}$ was found to proceed via the formation of oxycarbides $\rightarrow$ anatase/rutile $\rightarrow$ rutile and closely follows a third-order reaction path. The temperature window for activation of the oxidative decomposition of the $\mathrm{TiC}$ healing particles, i.e. for triggering the self-healing reaction, drops from 1000 to $400{ }^{\circ} \mathrm{C}$ as particle size decreases from $140 \mu \mathrm{m}$ to $50 \mathrm{~nm}$. As the change in optimal healing temperature does not depend on the chemical composition of the matrix material as such, the present study shows in a generic manner that extrinsic self-healing in oxide ceramic matrices can be tailored to a specific temperature range by tuning the size of the healing particle. Further, the activation energy required for oxidation decreases significantly for particles ranging between $10 \mu \mathrm{m}$ to $50 \mathrm{~nm}$. Above $10 \mu \mathrm{m}$ particle size, the activation energy for the thermal oxidation of $\mathrm{TiC}$ becomes constant.

\section{Acknowledgements}

This research was sponsored by the People Program (Marie Curie ITN) of the European Union's seventh framework programme, FP7, Grant No. 290308 (SHeMat). The authors are indebted to Ing. Ruud Henkdriks for performing XRD analysis.

Open Access This article is distributed under the terms of the Creative Commons Attribution 4.0 International License (http://creativecommons.org/ licenses/by/4.0/), which permits unrestricted use, distribution, and reproduction in any medium, provided you give appropriate credit to the original author(s) and the source, provide a link to the Creative Commons license, and indicate if changes were made.

\section{References}

[1] Yoshioka S, Boatemaa L, van der Zwaag S, Nakao W, Sloof WG (2016) On the use of TiC as high-temperature healing particles in alumina based composites. J Eur Ceram Soc 36(16):4155-4162. https://doi.org/10.1016/j.jeurceramsoc. 2016.06.008

[2] Boatemaa L, Kwakernaak C, van der Zwaag S, Sloof WG (2016) Selection of healing agents for autonomous healing of alumina at high temperatures. $J$ Eur Ceram Soc 36(16):4141-4145. https://doi.org/10.1016/j.jeurceramsoc. 2016.05.038

[3] Ando K, Kim BS, Chu MC, Saito S, Takahashi K (2004) Crack-healing and mechanical behaviour of $\mathrm{Al}_{2} \mathrm{O}_{3} / \mathrm{SiC}$ composites at elevated temperature. Fatigue Fract Eng Mater Struct 27(7):533-541. https://doi.org/10.1111/j.1460-2695. 2004.00785.x

[4] Osada T, Nakao W, Takahashi K, Ando K, Saito S (2007) Strength recovery behavior of machined $\mathrm{Al}_{2} \mathrm{O}_{3} / \mathrm{SiC}$ nanocomposite ceramics by crack-healing. J Eur Ceram Soc 27(10):3261-3267. https://doi.org/10.1016/j.jeurceramsoc. 2006.11.080

[5] Ono M, Nakao W, Takahashi K, Nakatani M, Ando K (2007) A new methodology to guarantee the structural integrity of $\mathrm{A} 12 \mathrm{O} 3 / \mathrm{SiC}$ composite using crack healing and a proof test. Fatigue Fract Eng Mater Struct 30(7):599-607

[6] Ando K, Chu MC, Yao F, Sato S (1999) Fatigue strength of crack-healed $\mathrm{Si}_{3} \mathrm{~N}_{4} / \mathrm{SiC}$ composite ceramics. Fatigue Fract Eng Mater Struct 22(10):897-903. https://doi.org/10.1046/j. 1460-2695.1999.00210.x

[7] Salas-Villaseñor AL, Lemus-Ruiz J, Nanko M, Maruoka DM (2009) Crack disappearance by high-temperature oxidation of alumina toughened by Ni nano-particles. Adv Mater Res 68:34-43

[8] Nakao W, Abe S (2012) Enhancement of the self-healing ability in oxidation induced self-healing ceramic by modifying the healing agent. Smart Mater Struct 21:1-7

[9] Farle A, Boatemaa L, Shen L, Gövert S, Kok JBW, Bosch M, Yoshioka S, Svd Zwaag, Sloof WG (2016) Demonstrating the self-healing behaviour of some selected ceramics under combustion chamber conditions. Smart Mater Struct 25(8):084019

[10] Lavrenko VA, Glebov LA, Pomitkin AP, Chuprina VG, Protsenko TG (1975) High-temperature oxidation of titanium carbide in oxygen. Oxid Met 9(2):171-179. https://doi. org/10.1007/bf00613231

[11] Stewart RW, Cutler IB (1967) Effect of temperature and oxygen partial pressure on the oxidation of titanium carbide. J Am Ceram Soc 50(4):176-181. https://doi.org/10.1111/j. 1151-2916.1967.tb15076.x 
[12] Shimada S (1996) A thermoanalytical study of oxidation of TiC by simultaneous TGA-DTA-MS analaysis. J Mater Sci 31:673-677. https://doi.org/10.1007/BF00367884

[13] Shimada S, Kozeki M (1992) Oxidation of $\mathrm{TiC}$ at low temperatures. J Mater Sci 27(7):1869-1875. https://doi.org/ 10.1007/BF01107214

[14] Favergeon L, Morandini J, Pijolat M, Soustelle M (2013) A general approach for kinetic modeling of solid-gas reactions at reactor scale: application to Kaolinite Dehydroxylation. Oil Gas Sci Technol-Rev IFP Energies Nouvelles 68(6):1039-1048

[15] Turkdogan ET (1977) Gas-solid reactions, J. Szekely, J. W. Evans and H. Y. Sohn, Academic Press, 1976. 400 pages. AIChE J 23(4):612-612. https://doi.org/10.1002/aic.690230 435

[16] Xu Z, Sun X, Khaleel MA (2012) A generalized kinetic model for heterogeneous gas-solid reactions. J Chem Phys 137(7):074702

[17] Brown EM (2001) Introduction to thermal analysis: techniques and applications, introduction to thermal analysis: techniques and applications, 2nd edn. Kluwer, Amsterdam. https://doi.org/10.1007/0-306-48404-8

[18] Khawam A, Flanagan DR (2006) Solid-state kinetic models: basics and mathematical fundamentals. J Phys Chem B 110(35):17315-17328. https://doi.org/10.1021/jp062746a

[19] Lyon RE (1997) An integration method of non-isothermal kinetic analysis. Federal aviation administration, U.S. Department of transportation

[20] Senum GI, Yang RT (1977) Rational approximations of the integral of the Arrhenius function. $\mathrm{J}$ Therm Anal 11(3):445-447. https://doi.org/10.1007/bf01903696

[21] Kissinger HE (1957) Reaction kinetics in differential thermal analysis. Anal Chem 29(11):1702-1706. https://doi.org/10. 1021/ac60131a045

[22] Kissinger HE (1956) Variation of peak temperature with heating rate in differential thermal analysis. J Res Natl Bureau Stand 57(4):217-221

[23] Gotor FJ, Criado JM, Malek J, Koga N (2000) Kinetic analysis of solid-state reactions: the Universality of Master plots for analyzing isothermal and nonisothermal experiments. J Phys Chem A 104(46):10777-10782. https://doi. org/10.1021/jp0022205

[24] Sloof WG, Delhez R, de Keijser TH, Schalkoord D, Ramaekers PPJ, Bastin GF (1988) Chemical constitution and microstructure of $\mathrm{TiC} x$ coatings chemically vapour deposited on $\mathrm{Fe}-\mathrm{C}$ substrates; effects of iron and chromium. J Mater Sci 23(5):1660-1672. https://doi.org/10.1007/ bf01115705

[25] Voitovich VB (1997) Mechanism of the high temperature oxidation of titanium carbide. High Temp Mater Process (London). https://doi.org/10.1515/HTMP.1997.16.4.243

[26] Kurlov AS, Gusev AI (2011) Effect of particle size on the oxidation of $\mathrm{WC}$ powders during heating. Inorg Mater 47(2):133-138. https://doi.org/10.1134/s0020168511020099

[27] Quanli J, Haijun Z, Suping L, Xiaolin J (2007) Effect of particle size on oxidation of silicon carbide powders. Ceram Int 33(2):309-313. https://doi.org/10.1016/j.ceramint.2005. 09.014

[28] Phuoc TX, Chen R-H (2012) Modeling the effect of particle size on the activation energy and ignition temperature of metallic nanoparticles. Combust Flame 159(1):416-419. https://doi.org/10.1016/j.combustflame.2011.07.003

[29] Fu Q-S, Xue Y-Q, Cui Z-X, Wang M-F (2014) Study on the size-dependent oxidation reaction kinetics of nanosized zinc sulfide. J Nanomater 2014:8. https://doi.org/10.1155/2014/ 856489

[30] Hugosson HW, Eriksson O, Jansson U, Ruban AV, Souvatzis P, Abrikosov IA (2004) Surface energies and work functions of the transition metal carbides. Surf Sci 557(1):243-254. https://doi.org/10.1016/j.susc.2004.03.050

[31] Villars P, Cenzual K (eds) (2010) Pearson's crystal datacrystal structure database for inorganic compounds. ASM International, Materials Park, Ohio, USA

[32] Šesták J (2011) Rationale and fallacy of thermoanalytical kinetic patterns. J Therm Anal Calorim 110(1):5-16. https:// doi.org/10.1007/s10973-011-2089-1

[33] Zhang W, Xue Y, Cui Z (2017) Size-dependence of surface thermodynamic functions of nano- $\mathrm{Cu}$ by dissolution kinetics. Colloids Surf A 533:81-86. https://doi.org/10.1016/j. colsurfa.2017.07.064

[34] Cui Z, Duan H, Xue Y, Li P (2015) An investigation of the general regularity of size dependence of reaction kinetics of nanoparticles. J Nanopart Res. https://doi.org/10.1007/ s11051-015-3017-2

[35] Fu Q, Cui Z, Xue Y (2015) Size dependence of the thermal decomposition kinetics of nano- $\mathrm{CaC}_{2} \mathrm{O}_{4}$ : a theoretical and experimental study. Eur Phys J Plus. https://doi.org/10.1140/ epjp/i2015-15212-4 